\title{
Information technology governance: an analysis of the approach in Ecuador
}

\author{
Andrés Gavilanes-Molina1, Vicente Merchán-Rodríguez ${ }^{2}$ \\ ${ }^{1}$ Facultad de Ciencias de la Ingeniería, Universidad UTE, Quito, Ecuador \\ ${ }^{2}$ Departamento de Ciencias de la Computación, Universidad de las Fuerzas Armadas - ESPE, Sangolquí, Ecuador
}

\begin{tabular}{l} 
Article Info \\
\hline Article history: \\
Received Jun 23, 2021 \\
Revised Oct 10, 2021 \\
Accepted Dec 16, 2021 \\
\hline
\end{tabular}

Keywords:

Archetypes

Enterprise approach

IT decision-making structure

IT governance

\begin{abstract}
This work aims to show the Ecuadorian IT governance reality using descriptive research to analyze the approach of IT decisions. Indeed, one hundred and one private and governmental organizations were surveyed to examine their IT governance approach through a decision-making matrix model of responsibilities. The purpose is to distinguish IT governance perspectives and archetypes for IT decision-making, so that we collect relevant information about decision-making of executives, IT executives, Clevel, and business unit leader business in a developing economy context. The survey results are conclusive; business monarchy is the centralized approach for decision-making in Ecuador. For instance, IT governance in Ecuador is different from other Latin American nations in terms of digital culture, maturity, and effectiveness. On the other hand, this work encourages practitioners and scholars to increase the research scope to create, adopt, or adapt IT governance decision-making models for low-income countries. This is another step on the ongoing discussion in the extant IT governance literature, rather than as a final answer. Finally, future work will analyze and contrast the past normality with the post-pandemic period in Ecuador. Hence, using a survey on Ecuadorian IT governance structures, practices and behaviors will show the IT governance changes, perceptions, and trends.
\end{abstract}

This is an open access article under the CC BY-SA license.

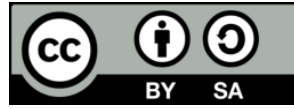

\section{Corresponding Author:}

Vicente Merchán-Rodríguez

Departamento de Ciencias de la Computación, Universidad de las Fuerzas Armadas-ESPE

Sangolquí, Ecuador

Email: vrmerchan@espe.edu.ec

\section{INTRODUCTION}

Firm commitment public and private organizations protect their economies from damage being caused by wrong Information Technology IT decisions, so they are seeking ways to enhance their organizational structure and decision areas permanently. In other words, everything that becomes a source of value must be directed, evaluated, and monitored [1] in these modern, competitive, and digital times. Nevertheless, there have been IT investment failures cases -e.g., useless and expensive infrastructure, architecture, and applications. Another example is those projects that had an enthusiastic start but were canceled before they even get out of the starting block.

Due to inefficient governance, companies are losing time, competitiveness, and human resources. IT governance is defined as specifying decision rights and liability to motivate desirable behaviors in the use of IT [2]. Thus, defining who is responsible for IT investment duties and who provides inputs, companies are reaching profits that are $20 \%$ higher than others with similar reality and environment [3], [4]. Specifying who is responsible for making decisions and align IT investments with business goals is the secret behind those 
higher profits. For this reason, companies should specify IT structure and requirements through designing, implementing, and maintaining ransformative leadership behaviors.

Effective IT governance practices are useful to reach the established objectives. Indeed, an organization should first analyze its business culture, preferences, priorities, and limitations. In essence, IT governance means effective development, management, and usage of IT based on agreements and strategic alignment with the business [2], [5]. Besides, strategic decisions pertinent to IT investments are crucial to success in business management [5]. To put it differently, IT is a strategic tool that eases business processes and opportunities. IT alignment adds value to the business in terms of process, people, and technology [6]. Indeed, IT governance is an integral part of information security and cybersecurity. The use of IT has been growing every year, so information security is convenient to protect what has been earned.

According to Weill and Ross [3], there is senior management awareness of IT governance processes in developed countries. Additionally, top performing firms have 60,70 , or $80 \%$ of senior executives aware of how IT is governed. In sum, it pays off if senior management levels know how to design, implement, and communicate IT governance processes [3]. In contrast, IT awareness in developing countries like Ecuador is different. There is a lack of knowledge about IT governance in Latin American countries [7], [8]. Furthermore, this empiric study shows that $90 \%$ of the surveyed companies only have $10 \%$ of IT collaborators. Indeed, there are big companies which IT budget does not go over $12 \%$. In contrast, when the critical organization's processes need IT primarily, the budget is $26 \%$ [7]. In consequence, instead of understanding the purpose of IT and using it for the established business objectives, some companies are focusing solely on regulatory compliance.

Related studies mention the importance of aligning the IT objectives with the strategic business objectives [3], [6]. In fact, IT governance is an integral part of organizational structure. Nonetheless, some Latin American countries are different from developed countries in terms of skills, dogma, and IT awareness [9]. The objective of this document is gathering the perceptions about IT governance from Ecuadorian IT professionals using a descriptive study. In like manner, this study identifies IT governance perspectives using a framework to represent decision rights and organizational arrangements involvement in a developing country context. Moreover, the present work contributes to the IT governance literature and help researchers and practitioners understand and use IT governance.

First, IT governance related works were collected and analyzed. Second, data through online surveys were gathered in Quito, Ecuador. The collected data were the participant's name and last name, job position, labor sector, duties, and organization's name. It is important to denote that the fill time for surveys was planned to take 10 to 15 minutes per person; nonetheless, it took 30 to 55 minutes in some cases because IT governance terms or strategic business objectives were unknown or unclear. Then, the methodology and Ecuadorian IT governance results were analyzed. In sum, a descriptive study was carried out to investigate opinions and perceptions about IT governance based on the processes, roles, and functions of the respondents.

The paper begins with an IT governance overview in section 2. Then, a description of the methodology that was applied in this study can be found in section 3. Subsequently, the Ecuadorian IT governance findings are presented in section 4. Ultimately, the paper concludes in section 5 with a discussion about IT governance and comments about future work.

\section{RESEARCH BACKGROUND}

Information Technology governance is not only relatively new term but also misunderstood. The research root started on 1950s when traditional organizational arrangements were reformulated [10], [11]. After, related works containing key words or titles such as information systems (IS) management, IT or IS Planning. It began to appear between 1950 and 1980 because of the increment of the use of IT according to [12]-[14]. Then, the importance of organization-wide strategic alignment was highlighted in the 1990s [4]. Until the late 1990s, J. Park et al. [4] started to use the term IT governance Framework instead of IS governance Framework. Of course, business and IT should work aligned; however, it is not a common pattern in the majority of the cases [8], [15]. In consequence, an effective IT governance pays more attention to principles, accountability, and prioritization to reach performance metrics [12], [16].

Although studies mentioned before had touched the topic previously, IT governance and a clear idea of strategic alignment were directly treated by using a contingency approach in the 2000s [4], [17]. Later, the Sarbanex-Oxley Act (SOX) generated deep transformations on other international legislations related to Corporate Governance. For this reason, not only developed countries but developing countries have been working on this challenging subject. The complexities that arose due to understanding the internal and external culture; addressing politics, and distributing power are present until now [4], [8]. Sambamurthy and Zmud [18], states that chief factors for governance are assessing IT risk, identifying and reporting the main organizational role of IT, shaping the proper colleague's capabilities, institutionalizing IT, and recognizing

Information technology governance: an analysis of the approach in Ecuador (Andrés Gavilanes-Molina) 
and responding to crucial organizational events. As expected, the highest business authorities should support and participate in the planning efforts to achieve the business strategy and overall objectives.

In 2005, J. Park et al. [4] developed a conceptual model for IT governance research based on an indepth review of the literature, so they conclude historical work on IT governance has two flows: IT governance archetypes and IT governance contingency analysis. Finally, Boynton et al. [16] revealed that researchers are deciding whether to maintain, aggregate, or reduce individual approaches to enhance the understanding of IT governance.

In consequence, Weill and Woodham [2] defines IT governance as: "the framework for decision rights and accountabilities to encourage desirable behavior in the use of IT." This definition is well researched, grounded, and accepted, so this work applies the concepts defined by [2], [3]. In other words, to choose who is responsible for making each decision and who has input rights are fundamental IT governance strategic tasks. Indeed, effective IT governance is relevant because it helps evaluate, direct, and monitor business processes, so as that achieve corporate goals. Naturally, there is a link between decision-making and organizational structures, so identifying, fixing, and conducting controls avoids IT investment losses.

IT governance arrangements refers to the authority patterns for main IT activities such as IT infrastructure, project management, and investments [16], [17]. Ansell and Gash [17] detected organizational arrangements such as corporate IS, divisional IS, and line management. Thus, IT opens the way to improve or boost an organization's processes and business relationships. Correspondingly, compiling studies is shown in Table 1 [2]-[4], [17]. Equally important, enterprises make decisions using organizational arrangements also known as archetypes; subsequently [2], [3]. Table 2 introduces six decision-making archetypes in order from more to less centralized.

Table 1. Key decisions aspects

\begin{tabular}{ll}
\hline \multicolumn{1}{c}{ Decision } & \multicolumn{1}{c}{ Definition } \\
\hline IT principles & IT purpose, desirable behaviors, role, and values. \\
IT architecture & Enterprise core business processes, relationships, degrees of integration, and technical capabilities. \\
Infrastructura strategies & Services, scalability, updates, leasing. \\
Business application needs & Markets and business process apportunities, app assessments, strategy alignment, product owner. \\
Investment and priorization & How much and where to invest. Strategy objectives and priorities. Strategic objectives alignment. \\
& Enterprise-wide and business units'priorities. \\
\hline
\end{tabular}

Table 2. IT governance archetypes

\begin{tabular}{cl}
\hline Styles & \multicolumn{1}{c}{ Who make decision } \\
\hline Business monarchy & Senior business excecutives (including CIO) \\
IT monarchy & Individuals or groups of IT excecutives \\
Federal & C-level manager and business representatives (i.e., central government and the states) \\
IT duopoly & IT manager and one group of business unit leaders \\
Feudal & Business units or process leaders \\
Anarchy & Each individual user \\
\hline
\end{tabular}

Depending upon the context, form, and requirements, the board should consider implementing COBIT [19], [20] or ISO 38500:2015 [1]. In detail, ISACA [20] has focused on IT domains and disaggregated them into processes and tasks. Meanwhile, ISO [1] defines the IT governance as a subset or domain of organizational governance, or in the case of a corporation, corporate governance. Due to these reasons, it is The Board's responsibility to delegate IT representation on board and IT manager level to plan, organize, monitor, measure, and assess. There is no single model or definition of IT Governance; nonetheless, avoiding assessment is a common practice [21]. In short, not only leaders but all organizations' collaborators should mainly make sure that IT Governance principles, overall vision, and objective occur and shall be natural; "do not just lead, govern!" [2].

Latin American IT governance needs to be enhanced [7]. Hence, decision rights and duties that encourage desirable behavior in the use of IT, such as trans parency, accountability, collaboration, and honesty, will permit enterprises to overcome challenging conditions, create innovative environments, and increase the business' productivity. Furthermore, planning, directing, evaluating, monitoring, and protecting critical processes organizations and local governments will make as many corporations as resilient as possible.

In Ecuador, Gavilanes and Merchan [8] shows the differences between Ecuador and Uruguay in terms of IT governance. Uruguay has demonstrated one of the best levels of IT governance maturity in the region, and the prevalence of IT governance in Ecuador compared to Uruguay's case is very variable in the 
last five years [8], [9]. Besides, Gavilanes and Merchan [8] noticed IT professionals often give highlights; however, top executives of the business make the majority of decisions. Because of that, there is a need to study IT governance in Ecuador from a different approach.

Regarding the current Ecuadorian reality in terms of economic, the governmental institution that controls private and public organizations in Ecuador [22] has published the 2019 financial balance sheets of the corporate sector. For example, the top five hundred enterprises have declared $\$ 74,196$ million in revenue (FY 2019). The largest economic sector is commerce ( $\$ 44,932$ million), followed by manufacturing industries ( $\$ 21,830$ million), the agricultural, forestry, and fishing sector ( $\$ 10,250$ million), and information and communication technologies (\$4,677 million). Additionally, the only economic sector that grew consistently is the fishing and aquaculture sector (10\%). In sum, the economy grew only $0,1 \%$ in a country that has 17 million people and an internet penetration of 57\% [23], [24]. Under those circumstances, IT governance realities and issues of each region are particulars. The implementation of management based on context represents managing in an effective way.

In addition, Reyes et al. [21] demonstrates that the Ecuadorian computer science scientific community is paying more attention to the IT governance research line. Furthermore, Aydin and Ulger [15] concludes that business, finance, and economics areas are also interested in IT governance. If multidisciplinary collaborations are enabled and promoted, the study and implementation of IT governance will generate better results in Ecuador. In sum, the background, need, and importance of IT governance drives the present and further research.

\section{RESEARCH METHOD}

This work analyzes who and what the key IT governance perspectives are. The instrument (questionnaire) for gathering IT governance information was surveyed [25]. This system for collecting IT governance perceptions was online. Indeed, the online survey software utilized was Survio [26]. The applied survey process was: i) setting specific and measurable objectives; ii) planning and scheduling the survey; iii) ensuring that appropriate resources are available; iv) designing the survey; v) preparing the data collection instrument; vi) validating the instrument; vii) selecting participants; viii) administering and scoring the instrument; ix) analyzing the data [25], and x) reporting the results [27].

Based on [3], five pivotal aspects of strategic IT decision-making and six IT governance archetypes were useful to structure the survey and ease the analysis process. The five utilized decision dimensions are: i) IT principles, ii) IT architecture, iii) infrastructure, iv) application needs, and v) prioritization and IT investment, plus the six archetypes used were: i) anarchy, ii) IT duopoly, ii) federal, iv) feudal, v) IT monarchy, and vi) business monarchy. Then, the collected IT governance data were explored and visualized using the Microsoft Power BI platform [28]. Indeed, the mentioned business intelligence (BI) platform was useful to connect to, model the collected data, reflect, and examine [29]. Additionally, the created data model will be helpful to add the next year's survey data, so the Ecuadorian IT governance practices and changes will be analyzed in time series. It is important to denote that [24] publish reports in Spanish, so that is the reason why the directory, financial balance, and the International Standard Industrial Classification of all Economic Activities (Clasificación Industrial Internacional Uniforme, CIIU) tables contain columns in Spanish (Figure 1).

Now, a user research activity [30] should represent the opinions, thoughts, and ideas of the user population. Ideally, research goes through a representative random sample of the population. Thus, the results are highly predictive for the entire population; however, this type of sampling requires precise methods that imply greater amounts of resources. In fact, this is rarely done in industrial settings and only occasionally in academic, medical, pharmaceutical, and government research [22]. The non-probability-based sampling strategy known as convenience sampling is often used in industry [30]. For example, [22] note that it is better to recruit participants from a convenient subset of the population rather than select participants from a large population. The population sample used reflects those that were available (or those that you had access to) at that time. There were 111 potential participants selected, of which $30 \%$ are from the public sector and $70 \%$ from the private sector, who were labeled related to the participant's job title. Then, all the collected data were visualized and interpreted in terms of decision rights, inputs, and archetypes. The participants are senior IT professionals, senior business executives, IT professionals, leaders of non-IT business units, business unit executives and leaders, IT executives, and other business groups who have worked for more than five years in Ecuador. It is important to note that the survey was in Spanish version because the participants are Spanish native speakers. Furthermore, the time to complete the online survey was planned to take 15-25 minutes per person. Participants were asked to identify the subject in which they work, their position, institution, and perceptions about IT at their workplace.

Equally essential for the current work, the COBIT 5 maturity model [19], [20] and ISO / IEC 38500: 2015 [1] helped understand and analyze the proper and desirable environment in the use of IT. For example,

Information technology governance: an analysis of the approach in Ecuador (Andrés Gavilanes-Molina) 
the main contribution that [19] made in this work is the distinct separation between governance and management in the interpretation of results. Additionally, [20] provides IT dimensions, values, and core processes that were beneficial in this study too.

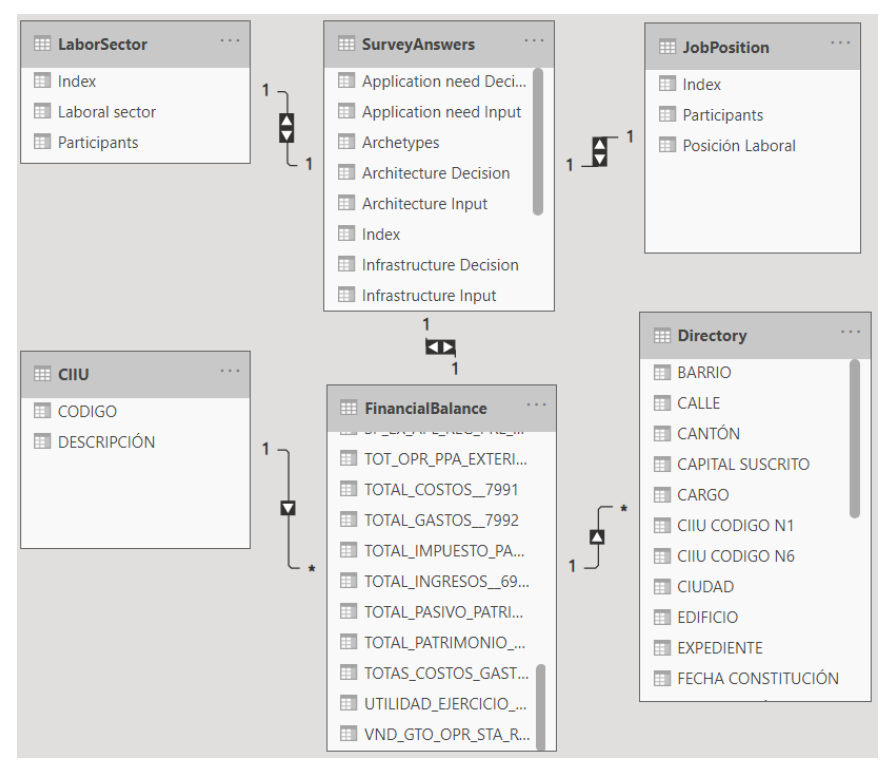

Figure 1. Data model

\section{RESULTS AND DISCUSSION}

The six archetypes and five decision aspects were conceptualized, applied, and proved. These elements were considered to structure the survey and analyze the IT governance in Ecuador. Having applied the online survey in the period between Sep 22, 2019, and Mar 08, 2020, the reports obtained are meaningful to understand the Ecuadorian IT governance practices. The first result, which was obtained from private and government companies in Ecuador, shows that 111 people were invited and 107 accepted it. Six companies did not fill the survey despite multiple affable reminders. In total, 101 people have turned in their answers. Thus, the percentage by job position is presented in Figure 2.

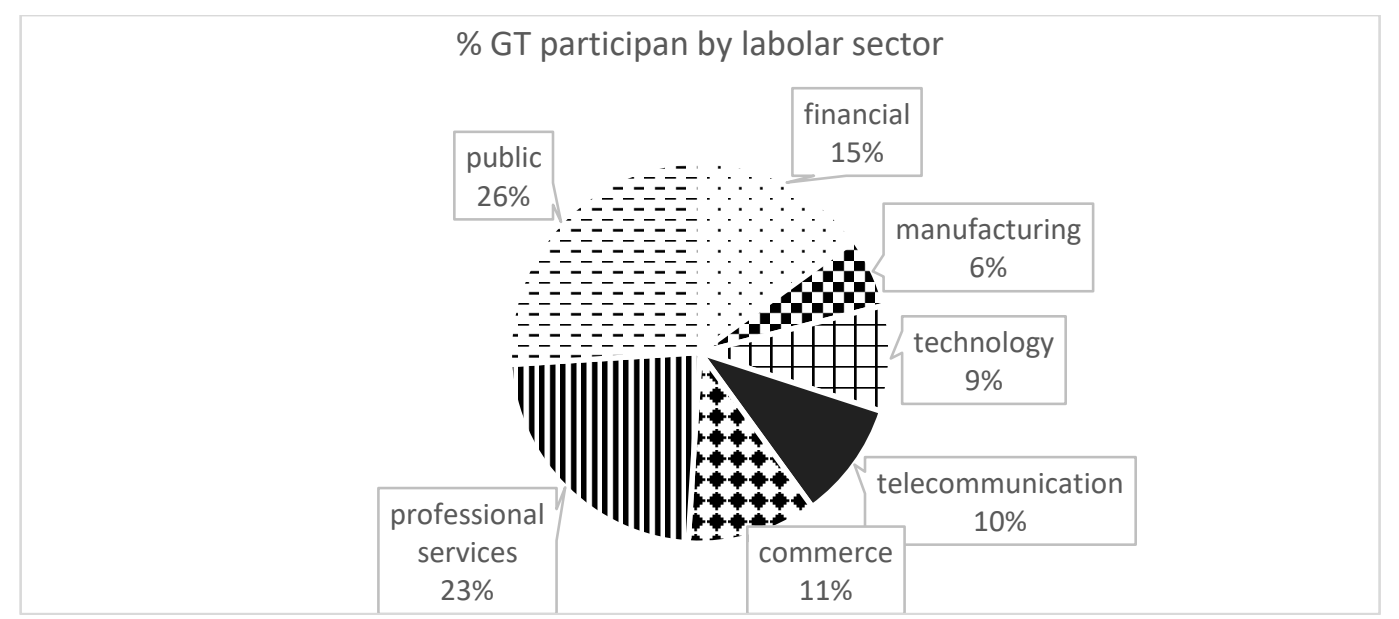

Figure 2. Percentage of the total by labor sector

Notably, the majority of participant were IT professionals. In detail, $52 \%$ represents the IT professional job position percentage, $21 \% \mathrm{C}$-level, and $6 \%$ were executives. In addition, Figure 3 shows the percentage of participants by labor sector. In this case, $25 \%$ of the surveyed companies are part of the service sector, $25 \%$ government, $11 \%$ commerce, $15 \%$ financial, $9 \%$ technology, and $6 \%$ manufacturing sector. 


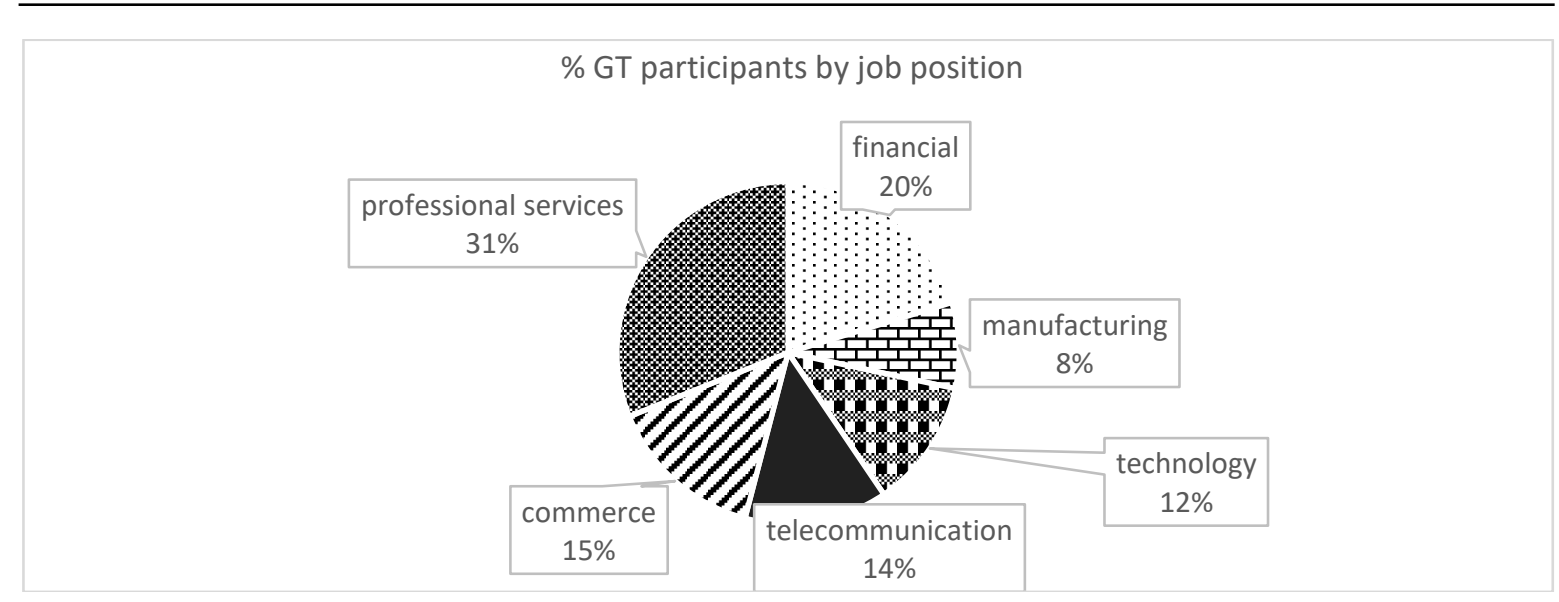

Figure 3. Percentage of the total by job position

In like manner, Figure 4 displays the decision aspects by archetypes. Architecture, infrastructure, application need, investment, and principle decisions were examined by the business monarchy, IT monarchy, IT duopoly feudal, federal, and anarchy. The percentages for observed IT governance archetypes' frequencies for five decision points are shown using a radar chart. Based on the collected data, the ruling archetype is the business monarchy. No doubt, the business monarchy is the most frequent archetype in Ecuador. In contrast, the most dominant archetype for infrastructure decisions is feudal (35\%). These results are different from the previous investigation (federal archetype was the most dominant followed by duopoly) in developed countries. Markedly, Figure 4 illustrates the involvement level of the established organizational arrangements for each decision. In other words, business executives including CIO are making investment, purpose, business application needs, architecture, and infrastructure decisions. The second most dominant organization arrangement (archetypes) to make decisions is feudal (business unit leaders), while anarchy is the least utilized archetype.

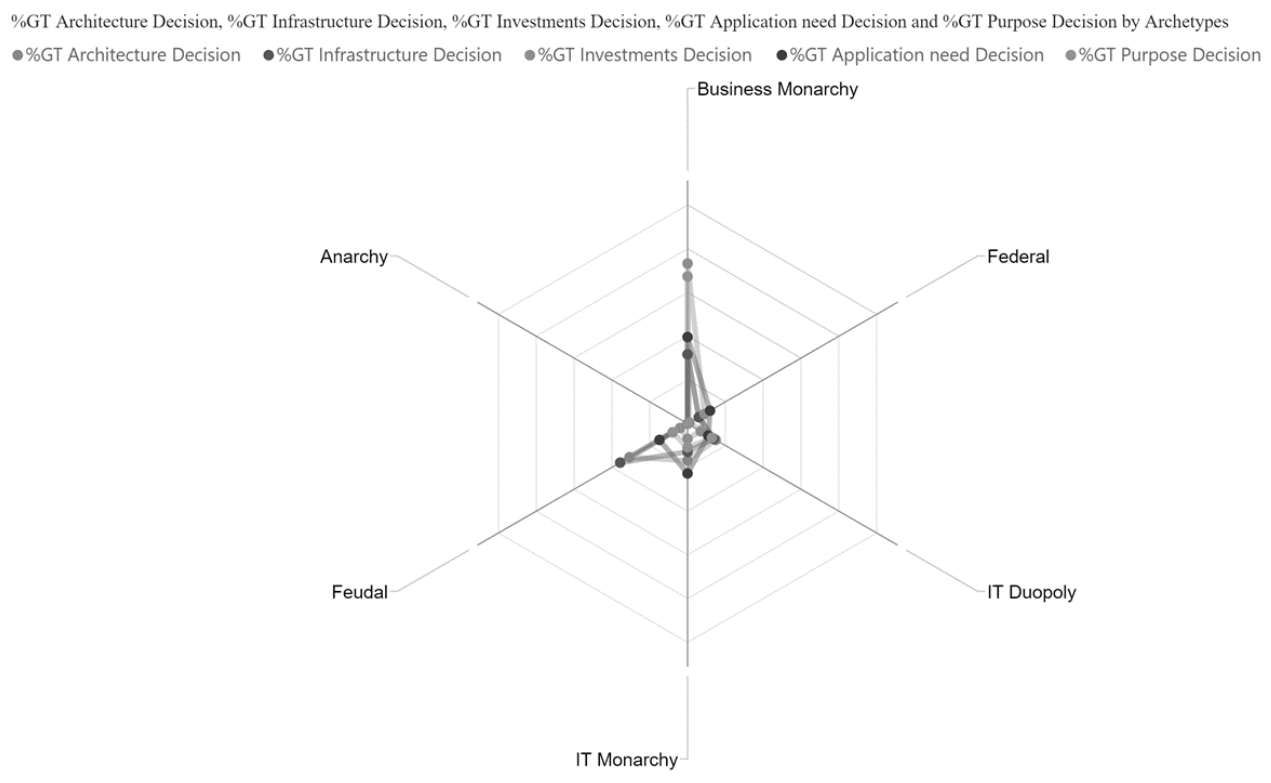

Figure 4. Decision aspects by archetypes

In contrast, Figure 5 displays which archetype is the most frequent in terms of giving useful information for decision-making. Hence, the most common arrangement for giving infrastructure inputs (38\%) and purpose inputs (26\%) are feudal. Besides, the most used organization arrange for giving business application need inputs (38\%) in Ecuador is IT monarchy. On the other hand, IT monarchy is the most frequent archetype for IT investment (26\%) and architecture inputs (39\%). 


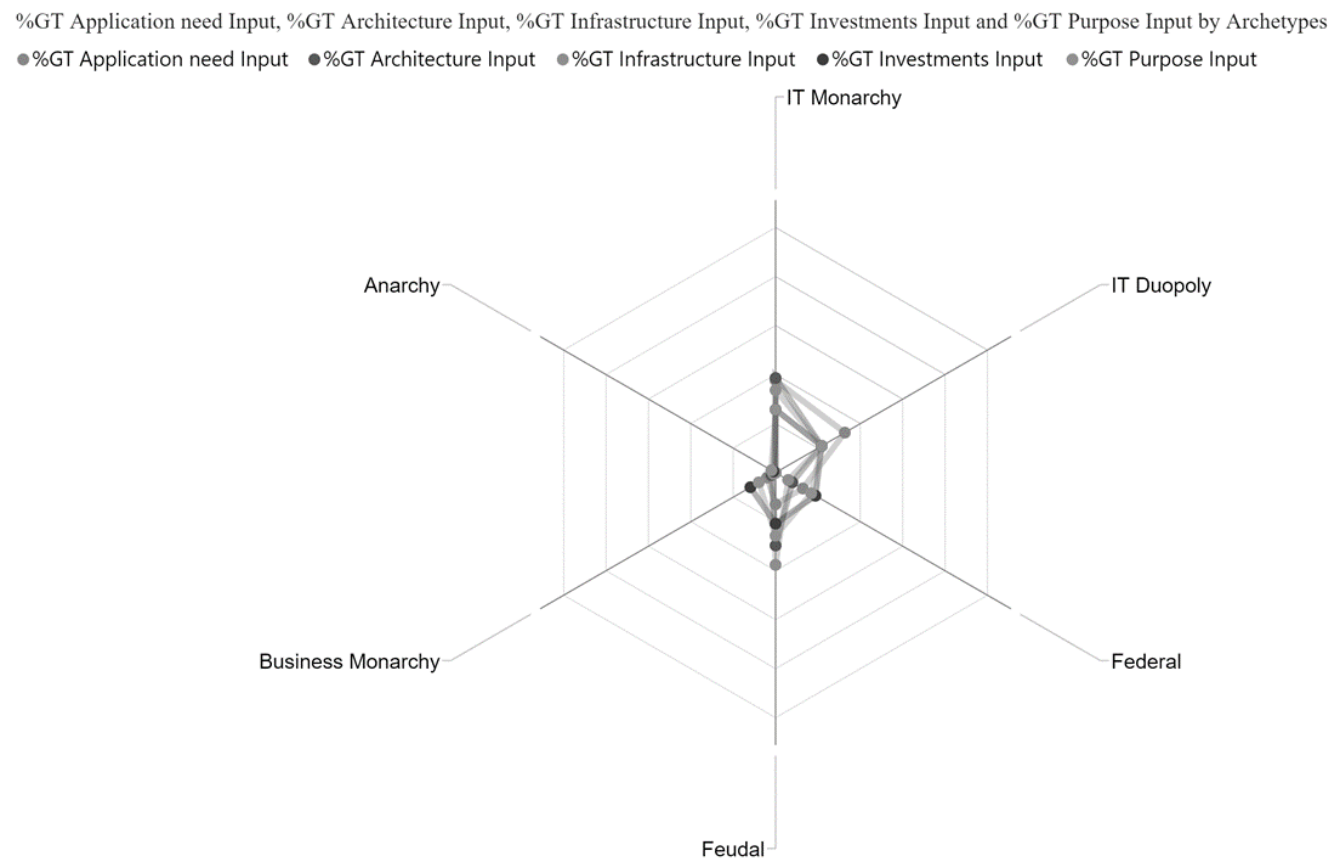

Figure 5. Input dominance of each archetype by decision

Regarding IT investment decisions, $73 \%$ of the participants mentioned that they make decisions using the business monarchy archetype, but just $12 \%$ of the participants who use this archetype provide information or inputs to make decisions (Figure 6). Furthermore, when the IT monarchy archetype is preferred, $7 \%$ of the participants make decisions about investment, but $26 \%$ provide investment inputs.

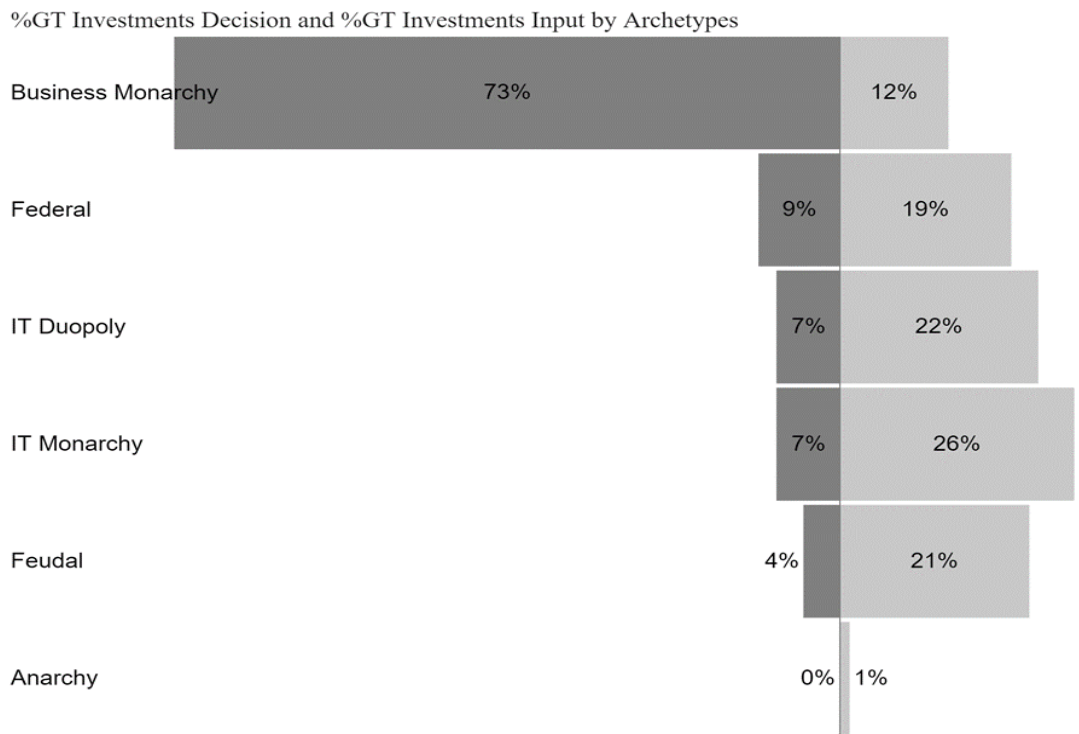

Figure 6. Investment decision compared with investment inputs by archetypes

In like manner, to depict the percentages of the outputs (decision-making) and inputs, archetypes are ordered vertically in Figure 7. The most dominant archetype appears at the top of the chart. In consequence, comparing the percentage of the total between infrastructure decisions and inputs, $36 \%$ of the participants make decisions by feudal. Nonetheless, the infrastructure inputs dispensing (38\%) are higher than making decisions. 


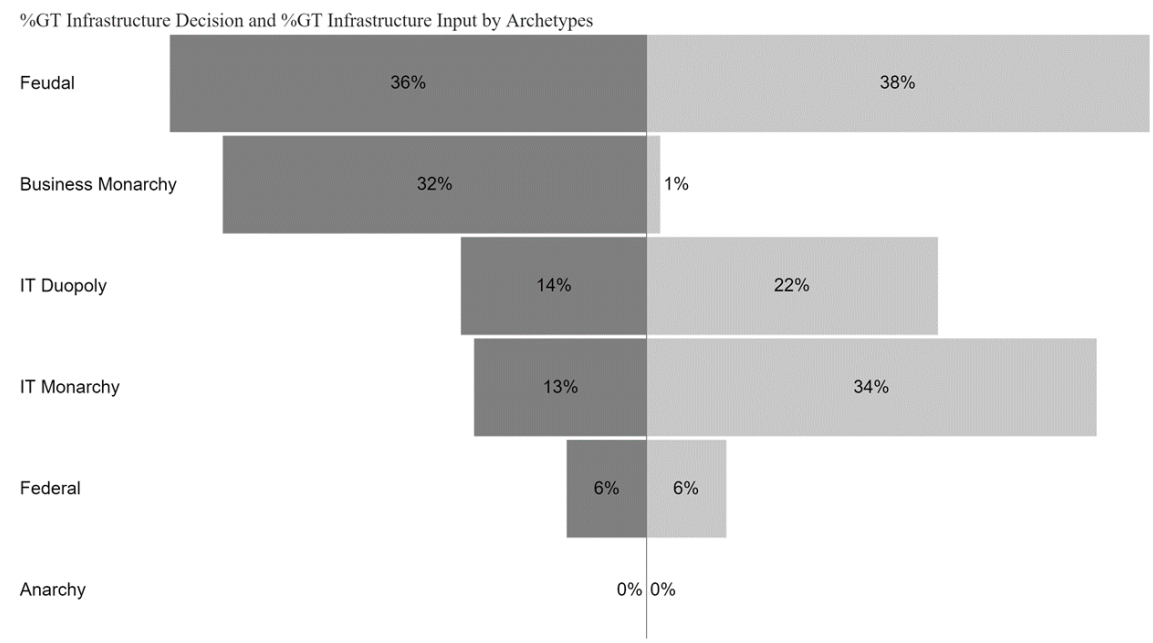

Figure 7. Infrastructure decision compared with infrastructure inputs by archetypes

As well, the comparison between architecture decisions and architecture inputs is presented in Figure 8 . In this case, business monarchy inputs represent only the $2 \%$, but $32 \%$ of the total they make decisions in that way. Likewise, participants highlighted that architecture decisions $(15 \%)$ and inputs $(22 \%)$ have almost the same degree of involvement when they use the IT duopoly archetype. When architecture decisions are made using a feudal archetype is almost balance. However, in the IT monarchy case, they provide more inputs (39\%) than decisions (17\%).

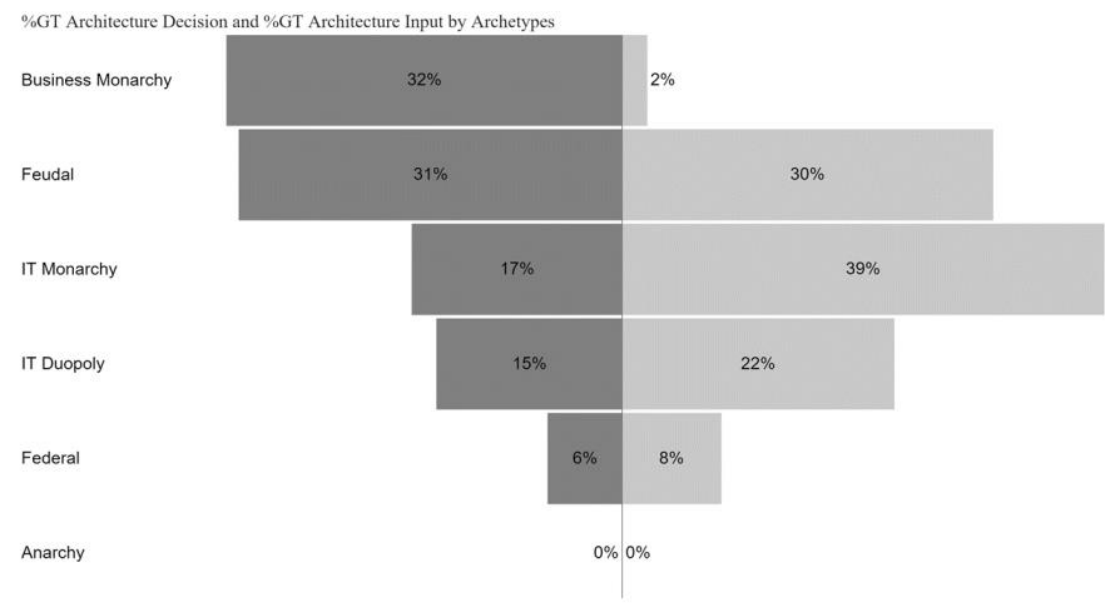

Figure 8. Architecture decision compared with application inputs by archetypes

After, a comparison between applications needs a decision, and inputs are shown in Figure 9. Application need decisions are fundamentally made by the business monarchy. When the business monarchy archetype is applied by surveyed companies, $40 \%$ make decisions and only $4 \%$ deliver out inputs. Another point to highlight is the IT monarchy, $36 \%$ of participants use this archetype to give information, and $23 \%$ to make decisions. Finally, in this case, none of the surveyed companies use the anarachy archetype. 


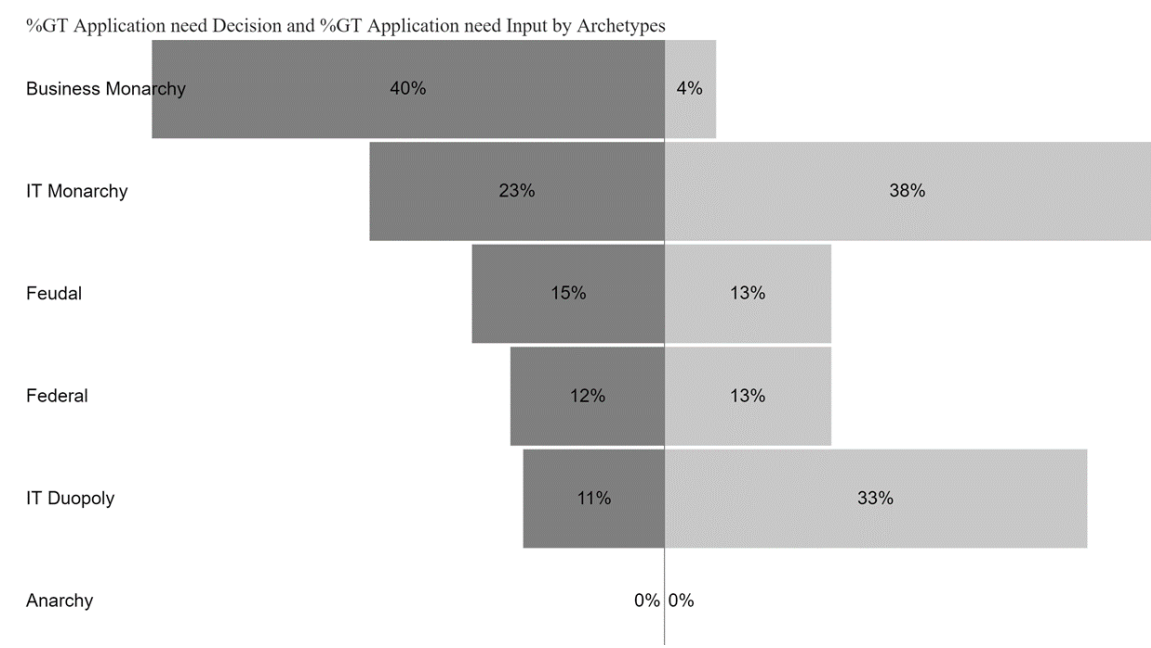

Figure 9. Application need decision compared with application inputs by archetypes

A key aspect is how companies are making decisions about principles. Notably, the business monarchy is the most domineering archetype to make decisions related to principles and business purpose. For example, $67 \%$ of participants work with this arrangement; nonetheless, $8 \%$ of surveyed deliver out inputs using this alternative. On the other hand, $8 \%$ of the respondents chose to make decisions using the feudal archetype, and 26\% provide inputs through this feudal way (Figure 10). Correspondingly, it is probably understandable why some technology projects and digital culture have not reached a wanted level in Ecuador. The international desirable standard use of IT is not a reality in Ecuador. Strategic and overall objectives should be protected from the economic damage being caused by wrong archetypes or strategy approaches.

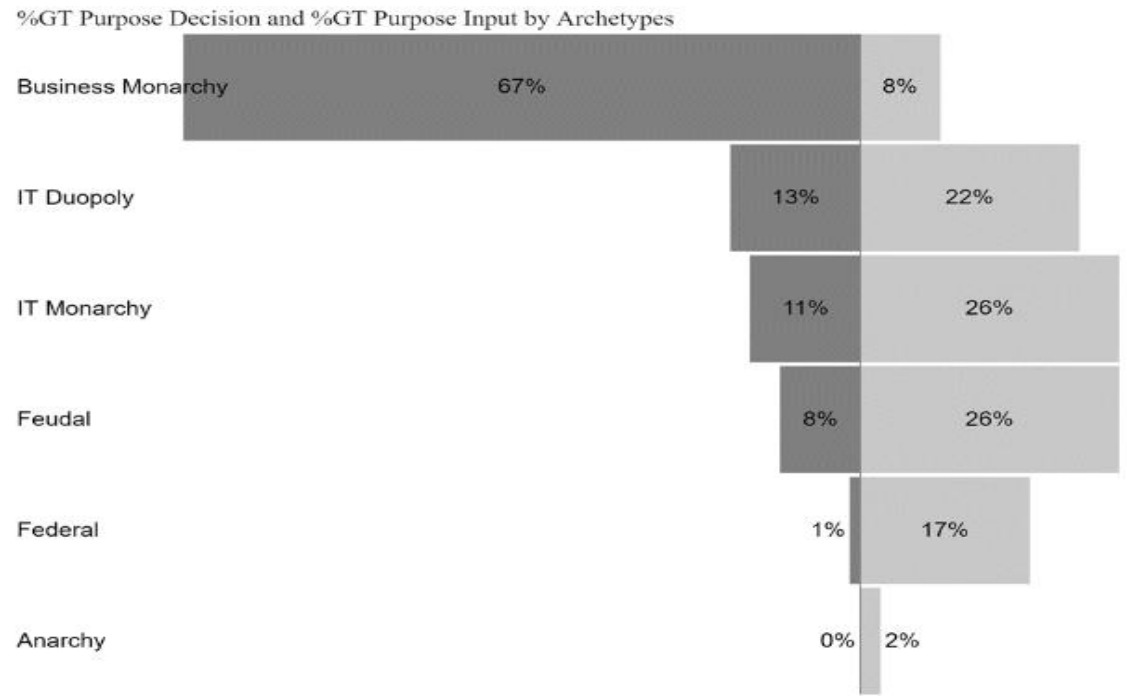

Figure 10. Purpose decision compared with purpose inputs by archetypes

\section{CONCLUSION}

The present content is updated as of March 2020. This work presents a snapshot of IT governance in Ecuador before the pandemic. In addition, this document is not regarded as offering a complete explanation of the matters referred to and is subject to changes in the overall corporate business environment. This paper provides IT governance highlights from Ecuador using a conceptual framework for IT governance. In conclusion, Weill and Ross's contemporary framework prompts the fusion of two streams, IT governance structures and IT governance contingency approach. In fact, researchers and practitioners are still seeking ways to improve their understanding of IT governance. Whether to continue with Weill and Ross's research 
approach or expanding on individual streams is still in discussion. Nonetheless, this paper aims to provide a multi-criteria approach based on a combination of the Well and Ross IT governance archetype model.

Thus, a combination of decision domains and archetypes was applied in this investigation to specify, analyze, and communicate where IT decisions are made. No doubt, the way how decisions are made impact the business. Consequently, this study is one of the first attempts to analyze IT governance practices in developing countries such as Ecuador. The chosen archetypes and decision aspects were useful to structure the survey. To identify who is responsible for IT governance perspectives, Weill and Ross's archetypes were applied successfully. Initially, 111 governmental and private companies were selected and directly asked to participate; however, 101 companies supported and delivered their answer. The purpose was completed through descriptive research.

In sum, the survey results show business monarchy is the most dominant archetype in Ecuador for decision-making. Nevertheless, feudal is the most common organizational arrangement for giving infrastructure inputs, architecture inputs, and purpose inputs. Notably, the investigation results about developed countries, cited in the background section, are different from a developing country's reality. For example, the federal archetype was the most dominant followed by a duopoly in developed countries. Furthermore, this research can be valuable to study other Latin American realities or IT governance patterns and changes. Due to the complexity and general lack of IT awareness, IT is often treated as a separately managed value-providing asset. For this reason, IT rarely receives the necessary attention of business executives. Consequently, the connection between the board and IT should be agile and trustworthy. Therefore, communicating core principles for effective IT governance is probably the most relevant action to create a greater awareness across the entire organization.

Effective IT governance means identifying the industry best practices, recognizing organizational culture, and applying the identified aspects based on the organization's environment. In other words, technology is important, but it is not all. A successful organization does not punish failures. In contrast, this organization matures its processes and invests in people's capabilities to reach a positive impact in terms of professional and personal development. Ultimately, Ecuadorian IT governance needs to be more transparent, studied, and rethought.

In the end, because of rapid digital innovation and transformation - e.g., widespread remote working and increasing reliance on agile approach - leading boards are approaching resiliency and stakeholders' trust. In this dynamic and quickly changing environment, tracing IT governance in Ecuador to visualize the next, and beyond will be the future work. The data model created for this study will be helpful to explore and contrast the pre-pandemic with the post-pandemic scenario. In short, a planned survey of Ecuadorian IT governance practices will be carried out at the end of the next year, so the future study will show the IT governance changes, perceptions, and trends in Ecuador.

\section{REFERENCES}

[1] ISO International Organization for Standardization, "ISO/IEC 38500:2015(en), Information technology — Governance of IT for the organization," Geneva, Switzerland, 2015.

[2] P. Weill and R. Woodham, "Don't Just Lead, Govern: Implementing Effective IT Governance," SSRN Journal, 2002, doi: 10.2139/ssrn.317319.

[3] P. Weill and J. W. Ross, "IT Governance on One Page," SSRN Journal, 2004, doi: 10.2139/ssrn.664612.

[4] J. Park, J.-N. Lee, O.-K. D. Lee, and Y. Koo, "Alignment Between Internal and External IT Governance and Its Effects on Distinctive Firm Performance: An Extended Resource-Based View," IEEE Trans. Eng. Manage., vol. 64, no. 3, pp. 351-364, Aug. 2017, doi: 10.1109/TEM.2017.2678485.

[5] Universidad Nacional de Colombia sede Manizales Universidad de Caldas, C. E. Marulanda Echeverry, M. López Trujillo, Universidad Nacional de Colombia sede Manizales, F. J. Valencia Duque, and Universidad Nacional de Colombia sede Manizales, "Gobierno y gestión de ti en las entidades públicas," administer, no. 31, pp. 75-92, 2017, doi: 10.17230/administer.31.5.

[6] P. Weill and J. Ross, "Four questions every CEO should ask about IT," The Wall Street Journal, Apr. 2011.

[7] H. G. Alberti, S. Ayala, and J. C. Verdun, "IT strategic alignment maturity model for SMEs case study: Uruguay," in 2012 XXXVIII Conferencia Latinoamericana En Informatica (CLEI), Medellin, Colombia, Oct. 2012, pp. 1-10. doi: 10.1109/CLEI.2012.6427214.

[8] A. Gavilanes and V. Merchan, "IT Governance Decisions in Ecuador: Realities and Differences," in 2019 International Conference on Information Systems and Software Technologies (ICI2ST), Quito, Ecuador, Nov. 2019, pp. 116-122. doi: 10.1109/ICI2ST.2019.00023.

[9] H. Garbarino and J. Verdún, "Análisis de la madurez en la toma de decisiones de TI en empresas PyMEs Caso de estudio: Uruguay,” AMCIS 2012 Proceedings, vol. 3, Jul. 2012, [Online]. Available: https://aisel.aisnet.org/amcis2012/proceedings/SpanishPortuguese/3

[10] W. R. King and R. W. Zmud, "Managing information systems: policy planning, strategic planning and operational planning," ICIS 1981 PROCEEDINGS, p. 11, 1981.

[11] P. Jönsson and M. Lindvall, "Impact analysis," in Engineering and managing software requirements, A. Aurum and C. Wohlin., Springer-Verlag, 2005, pp. 117-142.

[12] N. Bongani, "Performance Implications of Information Systems Strategy Planning within Zimbabwean Firms: a Context Approach," American Journal of Systems and Software, vol. 1, no. 1, pp. 1-10, 2013, doi: 10.12691/ajss-1-1-1. 
[13] A. E. Brown and G. G. Grant, "Framing the Frameworks: A Review of IT Governance Research," CAIS, vol. 15, 2005, doi: 10.17705/1CAIS.01538.

[14] F. Niederman, J. C. Brancheau, and J. C. Wetherbe, "Information Systems Management Issues for the 1990s," MIS Quarterly, vol. 15 , no. 4, p. 475, Dec. 1991, doi: 10.2307/249452.

[15] M. N. Aydin and C. Ulger, "Perception of IT Governance in an Emerging Market," International Journal of Computer and Information Technology (IJCIT), vol. 05, no. 01, p. 9, 2016.

[16] A. C. Boynton, R. W. Zmud, and G. C. Jacobs, "The Influence of IT Management Practice on IT Use in Large Organizations," MIS Quarterly, vol. 18, no. 3, p. 299, Sep. 1994, doi: 10.2307/249620.

[17] C. Ansell and A. Gash, "Collaborative Governance in Theory and Practice," Journal of Public Administration Research and Theory, vol. 18, no. 4, pp. 543-571, Oct. 2007, doi: 10.1093/jopart/mum032.

[18] V. Sambamurthy and R. W. Zmud, "Arrangements for Information Technology Governance: A Theory of Multiple Contingencies," MIS Quarterly, vol. 23, no. 2, p. 261, Jun. 1999, doi: 10.2307/249754

[19] J. F. Andry and A. K. Setiawan, "IT GOVERNANCE EVALUATION USING COBIT 5 FRAMEWORK ON THE NATIONAL LIBRARY,” Journal of Information Systems, vol. 15, no. 1, pp. 10-17, Apr. 2019, doi: 10.21609/jsi.v15i1.790.

[20] ISACA, "COBIT | Control Objectives for Information Technologies | ISACA.” https://www.isaca.org/resources/cobit (accessed Apr. 23, 2020).

[21] R. A. Enriquez Reyes, F. Valverde Alulema, and F. Llorens Larco, "Gobierno de las TI en las Universidades: análisis sistematico de la literatura científica y no convencional," IRJ, vol. 2, no. 8.1, pp. 397-411, Sep. 2017, doi: 10.33890/innova.v2.n8.1.2017.398.

[22] K. Baxter, C. Courage, and K. Caine, "Choosing a User Experience Research Activity," in Understanding your Users, Elsevier, 2015, pp. 96-112. doi: 10.1016/B978-0-12-800232-2.00005-5.

[23] BID, "Reporte Ciberseguridad 2020: riesgos, avances y el camino a seguir en América Latina y el Caribe | Publications," 2020.

[24] Superintendencia de Compañías, Valores y Seguros, "Portal de Información," 2020.

[25] S. L. Pfleeger and B. A. Kitchenham, "Principles of survey research: part 1: turning lemons into lemonade," SIGSOFT Softw. Eng. Notes, vol. 26, no. 6, pp. 16-18, Nov. 2001, doi: 10.1145/505532.505535.

[26] Survio, "Survio® | Online Survey Software | Create Free \& Beautiful Survey," Survio® 2020.

[27] T. C. Lethbridge, "A survey of the relevance of computer science and software engineering education," in Proceedings 11th Conference on Software Engineering Education, Feb. 1998, pp. 56-66.

[28] MSFT, "Power BI documentation - Power BI," 2020.

[29] PowerBI, "What is Power BI | Microsoft Power BI." 2020.

[30] K. Baxter, C. Courage, and K. Caine, "During Your User Research Activity," in Understanding your Users, Second Edition., Elsevier, 2015, pp. 158-189. doi: 10.1016/B978-0-12-800232-2.00007-9.

\section{BIOGRAPHIES OF AUTHORS}
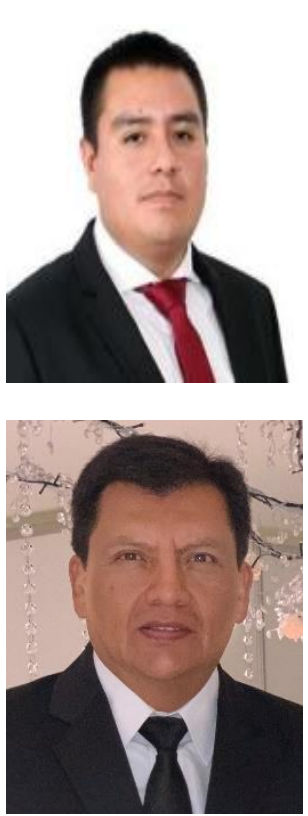

Andrés Gavilanes Molina (iD SC S P received the Informatics and Computer Sciences Engineering degree from the Universidad UTE, Quito, Ecuador, in 2017 and the master's degree in information security management from Universidad UTE, Quito, Ecuador, in 2020. His research interests include but are not limited to the following areas: information security, IoT, data analytics and visualization, and IT governance. Mr. Gavilanes collaborates within these fields as an author, co-author, and speaker, and he is a member of the Iberoamerican network of computer law. He can be contacted at email: gmaf1023784@ute.edu.ec.

Vicente Merchán Rodríguez (iD $8 \mathrm{SC}$ P received the Engineering degree in Systems Engineering from Universidad de las Fuerzas Armadas ESPE, Sangolquí, Ecuador, in 1996, the Master in Systems Management from Universidad de las Fuerzas Armadas ESPE, Sangolquí, Ecuador, in 2003, the Master in Telecommunication Strategic Management from the Universidad San Francisco de Quito (USFQ), Quito, Ecuador, in 2010 and the Doctoral degree in Informatics Science from the University of La Plata, La Plata, Argentina, in 2017. He joined the Department of Computer Science, at ESPE, to work as a part time professor. His current research interests are focused on the fields of eGovernance, information security governance, project governance, IT governance, quality assessment and telecommunications process. He can be contacted at email: vrmerchan@espe.edu.ec. 